\section{ENVIRONMENTAL TOBACCO SMOKE EXPOSURE AND CHILD NEURODEVELOPMENT}

\section{K. Polanska}

Department of Environmental Epidemiology, Nofer Institute of Occupational Medicine, Lodz, Poland

Background: In Poland about $30 \%$ of children is exposed to environmental tobacco smoke during prenatal period and more than $50 \%$ in postnatal one. Such exposure has serious health consequences including negative effect on child neurodevelopment. The aim of the study was to assess the effect of environmental tobacco smoke (ETS) exposure on child psychomotor development.

Material and methods: The study population consisted of children with well assessed prenatal exposure to environmental tobacco smoke (three times analysis of cotinine level in saliva of pregnant women). Assessment of child ETS exposure within two years after birth was based on questionnaires conducted with mothers, confirmed by biochemical verification of cotinine level in child urine. The cotinine level in biological samples was analyzed using Liquid Chromatography (HPLC) with Tandem Mass Spectrometry (MSMS). The Bayley Scale for Infant and Toddler Development (BESID-III) was used for the evaluation of child neurodevelopment.

Results: Multivariative analysis (including gender, birth order of the child and parental educational status) indicated the statistically significant association between child ETS exposure and cognitive development $(b=-4,0 ; p=0,04)$. ETS exposure has also negative impact on motor $(b=$ $2.7 ; p=0.2)$ and language $(b=-3.4 ; p=0.08)$ abilities of the child although the results were not statistically significant.

Conclusions: Maternal smoking was found to be related to a decrease child neurodevelopment although it impossible to separate the prenatal from postnatal exposure. All effort should be taken to eliminate the child ETS exposure.

\section{WORK IN GREENHOUSES AND INFANTS' BIRTH WEIGH}

\section{J. Jurewicz}

\section{Environmental Epidemiology, Nofer Institute of Occupational Medicine, Lodz, Poland}

Problem about exposure to pesticides is important in greenhouses where work is performed in warm microclimate during the most time of the year, involves usually moderately intense or heavy work. The working conditions in greenhouses might involve indirect exposure to pesticides resulting from contact with pesticide-treated flowers and vegetables.

Methods: 460 women who had been working for a period of at least 2 years in greenhouses in Poland were asked to participate in the project. We classified pregnancies of women working in, and out of, greenhouses on the basis of energy expenditure during mother's work into three groups: light work (200-700 kcal/shift); moderate work (701$1000 \mathrm{kcal} / \mathrm{shift})$; and heavy work (1001-1200 kcal/ shift). Information about application of pesticides was received from persons responsible for chemical protection in each examined greenhouse. Based on the Pan American Pesticide Database we identified pesticides which were classified as reproductive and developmental (RD) toxins.

Results: The study among women working in greenhouse revealed that the mean birth weight of infants whose mothers worked in greenhouse during pregnancy (work expenditure > $1000 \mathrm{kcal} /$ shift) was $177 \mathrm{~g}$ lower than that of those whose mothers worked out of greenhouse (light work < $700 \mathrm{kcal} / \mathrm{shift})(p=0.05)$. Mothers who during work in greenhouse were potentially exposed to RD pesticides, delivered infants with birth weight lower by about $70 \mathrm{~g}$. than infants' mothers not working at places where pesticides RD were applied, but these findings were not statistically significant.

\section{7}

\section{PRENATAL AND POSTNATAL CHILD EXPOSURE TO ENVIRONMENTAL TOBACCO SMOKE}

\section{K. Polanska}

Department of Environmental Epidemiology, Nofer Institute of Occupational Medicine, Lodz, Poland

Background: Environmental tobacco smoke exposure (ETS) is associated with poor pregnancy 